\title{
On a new approach to assessing the energy characteristics of substances
}

\author{
O. S. Sirotkin ${ }^{1, *}, A . M$. Pavlova $^{1}, R$. O. Sirotkin ${ }^{1}$, and A. E. Buntin ${ }^{1}$ \\ ${ }^{1}$ Kazan State Power Engineering University, Kazan, Russia
}

\begin{abstract}
Within the unified model of chemical bonding and methods of quantitative assessment of components of mixed chemical interaction between the elements in compounds, developed by the authors, a new approach was developed to assess the structural and energy characteristics of substances and fuels. It comprises establishing a correlation between the difference of bonds' chemical components of reactants and end products. Changes in the chemical bond components affect such characteristics of chemical reactions as the heat of formation of the reaction products, their redox properties, whether reaction is endo- or exothermic, as well as the heat of fuel combustion reactions. This approach is an additional reserve for improving the methods for assessing the energy characteristics of fuels and increasing the efficiency of energy production technologies.
\end{abstract}

\section{Introduction}

The issue of the efficient assessment of heat of combustion of substances and materials used as an energy source is the paramount task for modern industry and the life support of humanity as a whole. It is necessary to differentiate between the energy received by the mankind from space, that is, the energy of the Sun, and the energy contained in substances found in the atmosphere, hydro-, litho-, bio- and barysphere of the Earth. The sun is a constant, but not controlled by humans, source of energy, which is used as a heat source and for producing electricity in fairly limited quantities. Another promising source of energy for mankind is nuclear energy, which uses the physical energy of a substance, in the form of energy of bonds between elements of atomic nuclei (such as elementary particles) of radioactive substances (uranium, etc.). However, its main disadvantages are the limited resource base, the increased risk to the environment, as well as high costs of its production and waste disposal. This determines its contribution to the world energy production at a level of just about 16-18\%. Certain prospects have alternative energy sources based on use of mechanical energy of wind, river and sea water, thermal energy of volcanoes, biological transformations, etc., however, their contribution to global energy production is not significant yet.

As a result, the main source of energy on Earth is chemical energy (chemical power engineering), accumulated by nature in various types of chemicals, traditionally called fuels (wood, coal, peat, oil, fuel oil, gas, etc.). This is the energy of chemical bonding of elements (in the form of nuclei or atomic cores) of substances that dominate on Earth and form the basis of all the above-mentioned spheres of our planet in the form of about 15 million individual chemical compounds. The main advantage of chemical energy today is its availability and abundance of raw materials for its production, as well as the possibility of reproduction of raw materials in the form of wood and its derivatives. Therefore, the importance of deepening knowledge of features of various fuels' chemistry, as well as technologies for their use in the thermal and electrical power engineering and life support of mankind as a whole will never lose its relevance.

However, given the undoubted practical significance of chemistry and chemicals in power engineering and life support of mankind as a whole (plus materials, fertilizers, medicines, etc.), nowadays there is a huge problem of the lag in the development of fundamentals of this science. Moreover, there is still a shortage of attempts to develop a unified theory of chemical bonding and a system that combines chemicals into a single whole. The authors, within the scientific field they are developing, analyzed the causes of these problems and suggested their own solutions [2-9].

The production of chemical energy through its extraction from chemical substances is a process of chemical transformation of some chemical compounds of elements into others, accompanied by a thermal effect of various kinds (exo- and endo-) and magnitude. Moreover, this process is accompanied by breaking of chemical bonds between the elements in the reactants (characterized by energy of about $50-1250 \mathrm{~kJ} / \mathrm{mol}$ ) with subsequent formation of new bonds in the end products. Thermal effect depends on the difference in energy consumed when chemical bonds are broken in the reactants and energy released when bonds are formed in

\footnotetext{
* Corresponding author: sirotkin-49@mail.ru
} 
the reaction products. Traditionally, the thermal effect is estimated through enthalpy, entropy and temperature. Paradoxically, the assessment of the influence of chemical nature (composition, type of chemical bond and structure) of the reactants and the end products, which are chemical rather than physical, on their energy characteristics and chemical energy extraction processes, in fact, has not been carried out until recently.

The aim of this work is to develop a new approach to assessing the energy characteristics of chemical substances via revealing how they are influenced by their chemical nature, including the characteristics of chemical bonding, their structure, etc.

The difficulty of the task is determined by several reasons. This is primarily due to the lack of a universal theory describing the three main types of chemical bonding of elements within a single model, each of the bond type being modeled by its own theory/theories (valence bond theory and molecular orbital theory, band theory, ionic bonding theory). Moreover, all real bonds are not $100 \%$ covalent, metallic or ionic, but intermediate between two (homonuclear bond) or three (heteronuclear bond) types [2-10]. As a result, there are still no generally accepted methods for assessing the ratios of the components of chemical bonds, as well as there is lack of research on their influence on structure, energy characteristics of substances and the possibilities of endo- or exothermic reactions during their interaction with each other.

The solution of the aim set in the present work is based on a unified model of chemical bonding, comprising its covalent, metallic and ionic types, as well as the methods developed by the authors for quantifying each of these components in homo- and heteronuclear bonds [3-13].

All chemical reactions, for example, combustion of methane, take place at an electron-nuclear (chemical) micro-level of the substance organization, where, as a result of initiation (friction, arson, heat input, etc.), the type of chemical bond between elements inevitably changes when reactants are converted to end products. When new chemical substances are formed, this is accompanied by release (exo-) or absorption (endo-) of energy.

The first studies in this area were made by the authors using oxides as example, in which chemical bonds (due to the heteronuclear composition E-O) are characterized, within the framework of a single model of chemical bond [3-9], by three components: covalent character $\left(C_{C}\right)$, metallic character $\left(C_{M}\right)$ and ionic character $\left(C_{I}\right)$. It was found that the increase of $C_{C}$ and decrease of $C_{M}$ of homonuclear bonding in a series of substances formed by the elements of 4 and 5 periods of the periodic system, as well as in homonuclear bonds of $\mathrm{Zr}$, Mo, Sn, Te from left to right, generally leads to an increase in Gibbs energy $(\Delta G)$ of formation of the respective oxide [14]. That is, the smaller the difference in the covalent character and metallic character of the homonuclear reactants and oxygen and the smaller the ionic character of the formed E-O bond, the greater the energy of formation of the respective oxide. In turn, the Gibbs energy of the formation of oxides can be associated with the redox ability of the starting materials. The growth of $\Delta G$ upon oxide formation is associated with a decrease in the reducing ability of homonuclear substances (due to smaller values of electronegativity and metallic character of their bonds) in the reaction with oxygen, which reduces the likelihood of an exothermic reaction and increases the likelihood of an endothermic effect.

In power engineering, exothermic reactions of burning substances, in which large amount of heat is released, are of particular importance. Moreover, it is hydrocarbons and materials associated with them (gas, fuel oil, wood, peat, coal, etc.) that are the most important basis for obtaining energy today. In contrast to metals and ionic compounds, these substances have molecular structure, which is determined by the dominance of covalent character of chemical bond, as compared to metallic character and ionic character. The most important chemical reaction for obtaining thermal energy is the exothermic redox reaction of the combustion of hydrocarbons. In $[15,16]$, we for the first time evaluated the effects of chemical nature of substances on the probability of exothermal and endothermic reactions during their interaction with each other. Consideration of classical exothermic and endothermic chemical reactions of formation of the hydrogen chloride (1) and nitric oxide (2) by analyzing the difference in chemical nature of the homonuclear ('simple') reactants and heteronuclear end products showed the following.

$$
\begin{array}{r}
\mathrm{H}_{2}+\mathrm{Cl}_{2}=2 \mathrm{HCl} \\
\mathrm{N}_{2}+\mathrm{O}_{2}=2 \mathrm{NO}
\end{array}
$$

This can be seen that the difference $\Delta C_{C}$ and $\Delta C_{M}$ between chemical bonds of reactants [9] in reaction (1) is higher than in reaction (2). Therefore, with the growth of $\Delta C_{C}\left(\Delta C_{M}\right)$ in the reactants the likelihood of an exothermal effect increases. For convenience of understanding let us consider a number of simple redox reactions between hydrogen and halogens, where the type of chemical bond changes gradually in the group. The $\mathrm{H}-\mathrm{H}$ bond dissociation energy $\mid H^{\circ}{ }_{298}=450.94 \mathrm{~kJ} / \mathrm{mol}$. In the series of hydrogen halide formation reactions [15], depending on the oxidizing agent - halogen, in which from top to bottom $C_{c}$ decreases and $C_{M}$ increases in the group, there is an increase in the Gibbs free energy values, which indicates a decrease of the likelihood and rate of the reactions. The greater the difference $\Delta C_{C}\left(\Delta C_{M}\right)$ in the reactants, the more intensively halides are formed: energy of their formation $\Delta G$ decreases, and more heat $\Delta H$ is released as a result of the reaction. Moreover, as 
$\Delta C_{C}\left(\Delta C_{M}\right)$ decreases, starting from a certain value, the sign of the thermal effect changes, so that the reaction yielding $\mathrm{HI}$, unlike other hydrogen halides, becomes endothermic. In addition, in [15] the boundary of the transition of the formation of halides from the exothermic type to the endothermic type was refined. It is approximately equal to $12 \Delta C_{M}$ units. When ${ }_{\Delta} C_{M}>12$ the reaction is exothermic, at $\Delta C_{M} \approx 12$ an equilibrium occurs, while at $\Delta C_{M}$ below 12, the reaction proceeds with the heat being absorbed. At the same time, the halides with a more ionic bond type (HF and others) form more thermally stable compounds characterized by a smaller $\Delta G$.

Comparison of methane combustion, which is one of the most important reactions in chemical power engineering, with another chemical reaction - burning of ammonia (thus, two heteronuclear compounds) that has different type of bond than methane, showed the following [15].

$$
\begin{gathered}
\mathrm{CH}_{4}+2 \mathrm{O}_{2}=\mathrm{CO}_{2}+2 \mathrm{H}_{2} \mathrm{O} \\
\mathrm{NH}_{3}+0.75 \mathrm{O}_{2}=0.5 \mathrm{~N}_{2}+2 \mathrm{H}_{2} \mathrm{O}
\end{gathered}
$$

The $\mathrm{C}-\mathrm{H}$ bond in $\mathrm{CH}_{4}$ is characterized by higher metallic character $(42.84 \%)$ and lower ionic character $(2.36 \%)$ than $\mathrm{N}-\mathrm{H}$ bond in ammonia $(37.95$ and $7.21 \%$, respectively), that is, the electron density between elements in methane is more delocalized and metastable. Therefore, methane is more reactive and in air the reaction proceeds after activation ('ignition') independently with a release of large amount of heat. In the case of ammonia, the reaction under similar conditions occurs only with the presence of a constant source of fire.

Similar to the hydrogen halides discussed above, upon transition from reaction (3) to reaction (4) and decrease of $\Delta C_{M}$, the enthalpy of the reaction (- $\Delta H$ ) and $\Delta G$ increase, while its thermal effect decreases. This explains the lower reactivity of $\mathrm{NH}_{3}$ compared to $\mathrm{CH}_{4}$, and less exothermic effect of the ammonia combustion reaction.

The temperature of heat productivity $\left(t_{H}\right)$ is calculated according to formula [16]:

$$
{ }^{t_{H}}=Q_{c o m b} /\left(\sum V_{i p r} * C_{p i p r}\right)
$$

where $t_{H}$ is the temperature of heat productivity; $Q_{\text {comb }}$ is the heat of combustion; $V_{i p r}$ is volume of $i$ th reaction product; $C_{\text {prpr }}$ - molar heat capacity of $i$ th reaction product.

As the calculation of the temperature of heat production (combustion temperature) for ammonia showed, the temperature of combustion of ammonia in air is significantly lower than the temperature of its selfignition. This suggests that in this case, the released energy in the form of heat is not enough to sustain the reaction, and when the ignition source is removed, the reaction would die out. For methane, the combustion temperature is much higher than the autoignition temperature, and the reaction proceeds further independently.

In the case of combustion (oxidation) reactions, heterocompounds with lower $C_{I}$ and higher $C_{M}$ form more ionic compounds. Moreover, the greater the difference $\Delta C_{C}$ and $\Delta C_{M}$ of the reactants, the smaller the $\Delta G$ of the reaction and the greater the thermal effect $Q_{c o m b}$, which determines the rise of temperature of heat productivity $t_{H}$.

Next, an attempt was made to take into account the effect of stoichiometry, molecular mass, group bond components in hydrocarbons on their thermal characteristics.

In general, the redox reaction of a hydrocarbon combustion is given below.

$$
\begin{aligned}
& C_{m}{ }_{n}(g)+(m+0.5 n) O_{2}(g)= \\
& =m \mathrm{CO}_{2}(g)+0.5 n H_{2} O(g)+Q
\end{aligned}
$$

The values of group components of chemical bonds in the reaction products $\mathrm{C}_{\mathrm{Cgr}}, \mathrm{C}_{\mathrm{Mgr}}$ and $\mathrm{C}_{\mathrm{Igr}}$ according to the methods [8, 16, 17], taking into account the stoichiometry, vary in the following row: $\mathrm{O}_{2}$ (89.4; 10.6); $\mathrm{CO}_{2}(76.87 ; 16.14 ; 6.99) ; \mathrm{H}_{2} \mathrm{O}(54.07 ; 30.23$; 15.71). The difference between the components of chemical bond for the reactants (hydrocarbons and oxygen) is $\left(\mathrm{C}_{\mathrm{C}}, \mathrm{C}_{\mathrm{M}}, \mathrm{C}_{\mathrm{I}}\right): \mathrm{CH}_{4}(34.60 ; 32.24 ; 2.36) ; \mathrm{C}_{2} \mathrm{H}_{6}$ (33.94; 31.42; 2.52); $\mathrm{C}_{3} \mathrm{H}_{8}(33.63 ; 31.06 ; 2.57) ; \mathrm{C}_{4} \mathrm{H}_{10}$ $(33.44 ; 30.85 ; 2.59) ; \mathrm{C}_{5} \mathrm{H}_{12}(33.32 ; 30.72 ; 2.60) ; \mathrm{C}_{6} \mathrm{H}_{14}$ $(33.24 ; 30.63 ; 2.61) ; \mathrm{C}_{7} \mathrm{H}_{17}(33.17 ; 30.56 ; 2.61) ; \mathrm{C}_{8} \mathrm{H}_{18}$ $(33.12 ; 30.51 ; 2.61) ; \mathrm{C}_{9} \mathrm{H}_{20}(33.08 ; 30.47 ; 2.61) ; \mathrm{C}_{10} \mathrm{H}_{22}$ $(33.05 ; 30.44 ; 2.61)$.

With an increase of an alkane molecular weight in the series of hydrocarbons under study [16, 17], the number of elements (carbon and hydrogen) and their ratio increase. At the same time, the values of the group components for different hydrocarbons also change, but in different directions. That is, the values $C_{c g r}$ increase (in parallel with $C_{I g r}$, which stabilizes in the middle of the series at $2.61 \%$ ) and $C_{M g r}$ decrease, which, combined with the increase in the molecular weight of hydrocarbons and the number of bonds in them, leads to an increase in energy (determined through the enthalpy of combustion) released during the exothermic reaction of their combustion [17]. The maximum increase in the energy released during the exothermic reaction (by almost 2 times) is observed upon transition from the first (methane oxidation) to the second (ethane oxidation) 
alkane, with subsequent slowing down of this effect in a series of transformations from 2 to 10 hydrocarbons. This can be attributed to the maximum group $C_{c g r}$, $C_{M g r}$ and $C_{I g r}$ difference in these two hydrocarbons [17], which, combined with the maximum difference in the chemical bond components between the reactants ( $\Delta C_{c g r}, \Delta C_{M g r}$ and $\Delta C_{I g r}$ ), that is, these two hydrocarbons and molecular oxygen (see above) provides the greatest thermal effect. The article [17] showed that with $C_{I g r}$ increasing electronegativity difference increases, as well as the electronegativity of hydrogen and carbon increase from methane to decane. As a result, it was shown [17] that with an increase in molecular weight, C/H ratio, group $C_{c g r}$ and $C_{I g r}$ and a decrease in $C_{M g r}$ for a number of hydrocarbons, the value of the exothermic effect of their combustion reactions increases.

The approach developed has obvious prospects in the improvement of technologies for the production of thermal and electrical energy, optimizing the reactions of their production.

\section{Conclusions}

Within the framework of a unified model of chemical bonding and methods for quantitative evaluation of the components of mixed chemical interaction of elements in compounds developed by the authors, a new approach to assessing the energy characteristics of substances and fuels was developed. This approach implies establishing correlations between the difference in chemical bond's components in reactants and end products. As a result, it was found for the first time that the thermal effect of chemical reaction is determined by the difference in chemical bond types of reactants and end products. In particular, it was found that: - growth of covalent character and decrease in metallic character of homonuclear bond of the elements of 4 th and 5 th periods lead to the growth of Gibbs free energy ( $\Delta G$ ) upon respective oxide formation; - it is possible to use the difference in covalent (metallic) character values of chemical bonds in substances to assess the transition from exo- to endothermic type for reactions of formation of substances of one type (e.g., halides); - upon an increase in molecular weight, $\mathrm{C} / \mathrm{H}$ ratio, group $C_{c g r}$ and $C_{I g r}$ and a decrease in $C_{M g r}$ for a number of hydrocarbons, the value of the exothermic effect of their combustion reactions increases. This approach is an additional reserve for the improvement of methods for assessing the energy of various substances and fuels based on them to increase efficiency and improve energy production technologies.

\section{References}

[1] O.S. Sirotkin, Chemistry on the threshold of XXI century (Kazan, KSTU, 120) (1998)

[2] O.S. Sirotkin, Principles of unified chemistry (Kazan, Fen, 252) (2003)

[3] O.S. Sirotkin, R.O. Sirotkin, Chemistry (Principles of unified chemistry) (Moscow, KNORUS, 364) (2017)

[4] O.S. Sirotkin, Principles of innovative materials science (Moscow, INFRA-M, 158) (2011)

[5] R.O. Sirotkin, Physicochemistry of homoand heteronuclear substances and materials (Moscow, Ruscience, 236) (2018)

[6] O.S. Sirotkin, Principles of modern materials science (Moscow, INFRA-M, 364) - in Russian (2015)

[7] O.S. Sirotkin, R.O. Sirotkin, and A.M. Trubacheva, On the necessity and procedure of taking into account the metallic component of a heteronuclear bond. Russian Journal of InorganicChemistry.

50(1), . 67-71 (2005)

[8] O.S. Sirotkin, R.O. Sirotkin, A.M. Trubacheva, Characteristics of homo- and heteronuclear bonds of fine electron-nuclear structure and their effects on properties of metallic and nonmetallic materials (Kazan, KSPEU, 304 (2009)

[9] O.S. Sirotkin, R.O. Sirotkin,, and P.B. Shibaev, Effect of the character of homo- and heteronuclear chemical bond on the intermolecular interaction energy and properties of halogens and hydrogen halides Russian Journal of Inorganic Chemistry 56(7), 1104-1108 (2011)

[10] O.S. Sirotkin, R.O. Sirotkin, Multilevel structure and properties of metals and polymers within the unified model of chemical bond. Journal of Materials Science and Engineering A. 6(2), 71-74 (2016)

[11] R.O. Sirotkin, O.S. Sirotkin, I.V. Ivshin, A.R. Safin, A.N. Tsvetkov, Dolomanyuk. Titanium chemical nature features, which determine its most important performance properties in linear enginegenerator. ARPN Journal of Engineering and Applied Sciences. 11(16), 9664-9666 (2016)

[12] R.O. Sirotkin, O.S. Sirotkin, Physicochemical principles of universal methodology of

controlling structure and properties of metallic and nonmetallic materials. IOP Conf. Ser.: Mater. Sci. Eng., 327, 042119 (2018)

[13] D.Yu. Pavlov, O.S. Sirotkin, A.M. Trubacheva, R.O. Sirotkin, Chemical nature of homonuclear ('simple') inorganic substances, their redox properties and the effects on oxides formation Gibbs energy Herald of Kazan technological university 9, 3538 (2012)

[14] D.Yu. Pavlov, A.M. Trubacheva,, O.S. Sirotkin, R.O. Sirotkin, On possibility of assessment of the effects of inorganic substances' chemical nature on their energy characteristics News of the Universities. Issues of Power Engineering 3-4, 54-60 (2013)

[15] O.S. Sirotkin, D.Yu. Pavlov, R.O. Sirotkin, A.M. Pavlova, On the effects of chemical nature of substances on endo- and exothermic character of their 
reactions. Herald of Kazan Technological University, 24, 14-16. (2013)

[16] O.S. Sirotkin, A.M. Pavlova, R.O. Sirotkin, A.E. Buntin, On relationship between stoichiometry, group covalent, metallic and ionic characters of alkanes, and their energy characteristics, Herald of Kazan technological university, 21(2), 17-21 (2018) 